\title{
Spermatic Cord Obstruction, CTCAE 5.0
}

National Cancer Institute

\section{Source}

National Cancer Institute. Spermatic Cord Obstruction, CT CAE 5.0. NCI Thesaurus. Code C146757.

A disorder characterized by blockage of the normal flow of the contents of the spermatic cord. 